\title{
Spatial Orientations of Nomads' Lifestyle and Culture
}

\author{
Kaliakbarova Lyailya ${ }^{1}$, Smakova Zaure ${ }^{2}$, Kossanova Aigul ${ }^{3}$, Yermanov \\ Zhanat $^{4}$, Mashimbayeva Ainur ${ }^{5}$, Zhussupova Saule ${ }^{6}$ \\ ${ }^{1} \mathrm{PhD}$, Department of Music Education, KNC under Kurmangazy, Almaty, \\ Kazakhstan.Email: kaliakbarova.lyailya@gmail.com \\ ${ }^{2}$ Docent, Art History, Department of Kobyz and Accordion, KNC under Kurmangazy, \\ Almaty, Kazakhstan. \\ ${ }^{3}$ Docent, Department of Folk Singing, KNC under Kurmangazy, Almaty, Kazakhstan. \\ ${ }^{4}$ Associate Professor Of Conservatory, Department Of Wind And Percussion \\ Instruments, KNC under Kurmangazy, Almaty, Kazakhstan. \\ ${ }^{5}$ Docent, Social and Human Sciences, KNC under Kurmangazy, Almaty, Kazakhstan. \\ ${ }^{6} \mathrm{PhD}$, Department of Music Education, KNC under Kurmangazy, Almaty, \\ Kazakhstan.
}

Received October 14, 2017; Revised January 30, 2018; Accepted February 12, 2018; Published May o6, 2018.

\begin{abstract}
The nomad's model of the world is reasonable and rational; comprehending the universal laws, it often extrapolates its own qualities and structures to surrounding world (up to the cosmic scales). In creating the picture of a real world, the nomad endows it with meanings and values that go far beyond the ordinary everyday life. The aim of our research involves not only the depth of the study of certain aspect of historical and cultural era, but also the determination of the field of culture, where 'everything and everyone is connected'. It involves the determination of the role of nomadic spiritual culture in the world culture; the analysis of religion of the ancient Turks Tengrism; the relationship and mutual enrichment of Tengrism with a complex, multi-element nomadic culture. Without the study of cosmogonic conceptions of nomadic world, it is impossible to comprehend the spirituality, complex worldview of the ancient Turks.
\end{abstract}

Keywords: Tengrism, nomadic, Turks, culture, worldview

\section{Introduction}

The languages have changed, genes mixed, myths merged, but the dynamics of nomadic life did not lead to chaos. The energy was continuously accumulated by previous cultures' achievements afire and replacing them with 'the energy of new nations that have accumulated previous achievements' preserving the continuity of moral development. A bright example of that is a Tengrian type based on nomadic culture and distinguished by distinctive originality. We consider Tengrism in general as 'an open universal outlook, an implementation of socio-anthropological deflection of existence, preserving its inner grounds, acting as one of the factors of cultural and civilizational identification' (Ayupov, 2004).

Tengrism was the source of nomad's spiritual strength, Tengrian ideological system brought nomads to new historical stage. Tengrism is Turkic peoples' set of ideas about the world, about the life that they acknowledged before accepting Islam and Muslim faith. The religion is (c) AesthetixMS 2018. This Open Access article is published under a Creative Commons Attribution Non-Commercial 4.0 International License (http://creativecommons.org/licenses/by-nc/4.o/), which permits non-commercial re-use, distribution, and reproduction in any medium, provided the original work is properly cited. For citation use the DOI. For commercial re-use, please contact editor@rupkatha.com. 
based on the faith in Creator, that presumably emerged in the end of 2000000 - and the beginning of 1000000 B.C., ensured the inviolability of Tengrian worldview traditions in nomadic environment, acceptance of oneself as a part of nature, a unity within nature. 'As a nomadic pagan religion, Tengrism existed for several millennia maintaining the stability of main theological trends and religious practices' (Bawden, 2009).

The idea of Tengri was based on animistic beliefs about the celestial spirit, as a nonpersonified masculine divine principle, the sky was conceived to be its actual manifestation, its dwelling place. Tenir - the Creator of the world and the world itself; he rules over the Universe, including all celestials, spirits and people.

In Kyrgyz language it is called Tenir, in Alt. Tenri, in Yakut Tanra, Tanara, in Mongolian Tener, in Buryat Teneri, in Karachay-Balkar Teiri, in Kazakh Taniri, in Tuvinian Deyer, in Chuvash Tura, in Shumerian Dangir, Dingir, in Japanese Tenno, in Chinese Tyan-Di, in Bulgarian Tanra, in ancient Xiongnu from Chinese sources - Chenli; In ancient Shumerian language and in the Polynesian Pantheon we can meet Tengri and its variations - Tanir, Tengrija, Tanara, Dingi, Tangaroo, in ancient Turkic language Tanir means 'God', 'Celestial God', 'Supreme deity', 'Eternal reality' (Morgan, 2000).

Tengrism and Tengrian worldview constituted diversity of religious ideas: the idea of monotheism - Tengri is considered as a single God; the worship of the sky and natural phenomena as a manifestation of natural religion; the idea of transcendence of Tengri as a comprehensive impersonal beginning, all-pervading impersonal power.

In ancient nomadic language, Tengri was the synonym of 'Universe' and was associated with both the God and the luminaries, the Sun and the Moon. The word Tengri is proto-Turkic, later it passed to Xiongnu language; it consists of two radicals Ten and pi, the first means 'sky', the second - 'a man'. In modern Turkic languages, the word ep, ip means 'men'. The term tan in Xiongnu and ancient Turkic language means 'dawn', 'sunrise', 'the beginning', 'when everything shines', when 'everyone wakes up and starts living' (Kashgari, 2005). In Xiongnu and ancient Turkic language, tan, ten means 'dawn', 'sunrise', 'lightening' (Bezertinov, 2004). In Yakut language, tang, tangar means an action 'to collect', 'to model', 'to construct'. There are other hypotheses as well. For example, the word aar or aar is translated from Yakut language as 'divine', which probably dates back to Saka language, because in Ossetic language, ard means 'deity'. It is possible that Tan-ara meant 'the God of the heaven'.

Fedorova's (2011) interpretation of the word combination Ayyy Tangara is of interest: 'ayyy (creation, to create, creator) means "a constructor", "an architect" of the universe - of the nature, sky and cosmos'. Ancient Turkic word Ten, Teng (equal, the equality of creator and his creation, spirited sky) is the space of the Higher being; a man created by God, who created the idea of spirituality, realized the sacred world of the eternal spirit by various means. Tenger means 'transcendental existence', 'the extraordinary power of transcendence' (Gantuya, 2011).

Tengri is an alpha that vitalizes everything; it is the life principle, the life itself. 'He is not just a sky; he is not just the God of the heaven and not just the Creator. Tengri is a "great beginning", an unattainable and unknowable Absolute Truth, the Absolute Spirit that cannot be rationally determined' (Abaev and Ayupov, 2009). No other landscape conditions offer a complete and holistic perception of the sky as the Central Asia does; it's no wonder that hence, there emerged an amazing God of the heavens - Tengri, an invisible and omnipresent king of the Universe, the creator of cosmos, humans, animals, the lord of the Universe, creator of the world. 
The eternal blue sky, endowed with sacredness; in Turkic language, kök originally meant a 'transcendental entity that covers the space - cosmos - sky; the life - nature - human being'. The sky was perceived as the absolute remoteness, the vastness, immensity; in human's mind, it is associated with axiological properties: 'transcendence and incomprehensibility, greatness and superiority over all the earthy, an all-seeing eye; from the sky we come - to the sky we go' (Tokarev, 1990). 'In ancient times, the traditional beliefs developed the idea of the absolute, the sacred, divine beginning. This sky was a supreme deity. The sky, in this perception, is an infinite space' (Khomushku, 2005). One of the hypostasis of the concept of the sky is a mythologeme of celestial light manifested by a semantic complex of celestial lightful deity, the worship of the heavenly bodies (Makarova, 2013).

In ancient Turkic language, the word kök (blue) is the synonym of Tengri; 'the essential meaning of the concept kök is the "beginning of life", hence, there has emerged the notion Kök Shykty. Kökirek - "soul", "spirit"; kökey - "memory", "consciousness"'. When nomad is convinced in something or realizes something, he says, 'Kökeyge kondy' (it was settled, nestled in mind). Here we see an amazingly flexible assumption of macro and micro worlds. All notions are generated in the sky and only then they are 'nestled in minds', - 'give a hermeneutic interpretation of a key constant of the word kök' (Kodar, 2012). Nomads, looking up at the sky, used to ask for support from the spirit of the sky, 'Tenirge tapsyrdym' (I give up for spirits' will). Blessing the wedded couple, they said, 'Tenir bless you!', 'Tenir zhalgacyn', 'Heaven bless you!'. If it needs to punish someone, they used to say, 'Tenir ursyn!', 'Heaven will punish you!'. Living in a temporary material world, they built harmonious interaction with the immaterial, spiritual principle - with the spirits of places, deceased ancestors, with the universal spirit, allencompassing divine Tengri.

An inscription on the monument of Kul tigin, the monument of Old Turkic runic writing, is an indicative of the idea of the Universe creation in ancient Turks' outlook:

When a blue sky emerged (or was created) above and a brown earth appeared underfoot; human sons appeared (or were created) between them. Along with the idea of the Universe creation, they had a clear belief on the man's place in this Universe: the sky that is above is a God himself and His abode at the same time; the earth is underfoot, and the man is in the middle (Stebleva, 1976).

Interestingly, in 'Ancient Turkic dictionary' the word turk is interpreted as 'God', 'master', 'principle', 'truth', tur means 'Turkic', 'power', 'authority', turk - 'strong', 'mighty' (Nadelyaeva et al., 1969). Before becoming an ethnonym, the word 'turik, turk, toruk was a noun meaning "God" (Lord), "master", "principle", "truth", as well as an adjective meaning "divine", "sacred", "true”, "real"' (Suleymenov, 2002).

The ethnic and social processes, material and spiritual culture of traditional nomadic society are based on nomadism. The history of nomadism is the relationship between man and nature. Nature nourishes and reproduces national integrity; it creates history; learning to read the book of nation's genesis, we can determine world outlook peculiarities of this nation. Nomadic lifestyle, dependent on natural-geographical conditions, was based on the movement, household organization.

The world of ancient nomads is complex and diverse; it includes a wide range of phenomena - from celestial bodies, natural objects to home and food, and interprets them in spatial, temporal, moral-ethical, social, kinship and sacred categories. In determining nomadic culture of thinking, we can determine the uniqueness of their traditional culture. As an 
independent, self-sufficient, classical type of nomadic civilization, nomadism rendered a great influence on the culture, in general. The culture of nomads, their traditional way of thinking was a cosmic worldview, a harmonic balance with nature, cosmic rhythms, 'the journey' into the spiritual realms among the elements and the ancestors' spirits (Kodar, 2012).

At the same time, paying attention to the peculiarities of space perception in the traditional Turkish culture and great influence of Tengrianism on these representations, the authors of the previous studies have only marginally concerned the issue of integrated Turkic culture model in the context of spatial Universe.

\section{Methods}

The authors combine a source study analysis of scientific sources on this issue with high-quality content analysis. The contextual basis is the Turkish folklore and features of nomads' material and social culture, in relation to which theoretical discourses acquire new meanings.

\section{Results}

The spiritual core of the world outlook of ancient nomads was contemplation, communication as a world attitude, a method of relations' formation with nature, with the Universe. Contemplation, involving the imagination, is a way of understanding the existence, where microcosm is a man and the macrocosm is the Universe that are in a harmony, determined the preservation of spiritual values' natural purity. The idea of the unity of man and nature is fundamental for many Eastern cultures; 'Eastern society is characterized by figurative thinking, closely linked to nature in contrast to the West with their tendency to create artificial habitat' (Gribb, 2004).

In comprehending the surrounding world, in building a relationship with it, nomads did not impose their own interpretations to the world, but treated it as a spiritualized reality. Their mind drew up some 'field of imagination' that created a real context for social practices. We consider the phenomenon of Tengrian worldview as the result of the promotion of 'imagination field'.

Imagination as a social process is not just a fantasy or a dream, a world of dreams; it has become a field of social practices, a form of activity, form of negotiations between local canters of personal activities and global fields of opportunity (Morokhoeva, 2014).

The field of imagination with temporal nature of cycles and rhythms is on the surface, but is not amenable to interpretation in familiar terms. In other words, we are dealing with a completely different logic - the logic of the process based on temporality (Makarova, 2013).

This type of mentality assumes a completely different form of relationship between man and higher forces - no dogmas and strictly regulated ritual practices, as it is accepted in world religions. The nomads communicated with the spirits on an equal footing, treated the sky respectfully, but without reverence and abjection, selecting the necessary forms of communication that are relevant and effective here and now.

The natural ways are dominant in the hierarchy of axiological values. Viewing the world as an infinite space, eternity, trying to understand it, the nomads lived by the principle of coexistence with the world. Mountainous terrain, alpine pastures, the vast steppe were the lands of classical nomads, 'the cradle' of nomadic culture, where the harsh way of life was combined 
with a strong desire of spiritual way (Barfeld, 2011). Sensuously perceived world of nature and the Universe was the basis that formed nomadic world outlook and attitude.

The cosmicality of nomadic world outlook assumes a special sensibility in relation to nature, when the nature is treated as a higher power giving lives and the continuation of the man. The nature and man merges into an organic whole... The nature is remarkably psychological in nomad's perception, because it projects moral principles of human existence: the sky is associated with eternity, mountains - with wisdom, water - with the life itself, and its source (Abdrasulova and Urmanbetova, 2009).

The cognition of the world was carried out in constant motion that is a series of transitions from one space to another due to seasonal migrations. The space, as a mobile category, and spatiality, as a characteristic feature of nomadic thinking, had a special meaning. Nomad was always on a way leading to infinity: on the way, they gave birth to their children and brought them up, the young men mature and the old pass away..

The dynamic form of nomads' existence formed the ideological concept of the way - zhol. The philosophy of way as spiritual transformation plays a big role in nomad culture. The nomad's zhol is akin to 'the warrior's way' of American Indians. It is a way of nomad's eternal movement in space and time as a way of accumulating wisdom and military skill.

As soon as the nomad's child gets on his feet and makes first steps, a ritual of 'cutting hobbles' is performed; this ritual symbolizes the way opening, the path in front of him, and realization of his own destined path. The elder say their wishes, Zhol bocyn (Let your way be successful), Zholyn ashyk bolsyn (I wish you have a clear way). Throughout his life, the nomad is mindful of his path and consciously implements what he is destined to be, accompanying each step, life stage, with special ritual practices. 'There was a Tengrian tradition of ascension - special Central Asian spiritual path, which had many levels of Initiation' (Urbanaeva, 1997). The constant movement in space and time determines the specificity of perception of these categories. Spacetime constants of the Turkic world (Heaven, Earth - Water; Way; World Mountain and the World Tree), acquiring the status of concepts, comprise a consistent and sustainable structure based on the concept of Tengrism.

\section{Model of nomads' cosmological ideas}

Tengrism and its individual elements like shamanism, magic, the cult of ancestors, hospitality, hunting cults, cults of animals, family rites, spatial model of the world, world tree, as elements of a single spiritual system and worldview, influenced the nomad's life.

The cosmological representations of nomads are based on spatial-temporal model of the world:

The Universe represents three-level space: the upper, middle and lower worlds. Each of the worlds is correlated to different classes of phenomena: the upper world - tree crown, the sky, the luminaries, the top of the mountain, the source of the river, birds; the middle world - a tree trunk, valley, mountain, people, animals; the lower world - the roots of the tree, cave, gorge, water (Toporov, 1987).

Proceeding with the descriptions of three worlds, some researchers (Lvova et al., 1988) correlate the upper, middle and lower worlds to the following realities: future - present - past; descendants - living generation - ancestors; fertilization - life - birth; the male principle - 
connection of the male and female - the female principle. Each of the worlds has its own characteristics, for example, the upper world is divided into horizontal tiers, 'inhabited' by the stars, luminaries, spirits; it has 'the bottom of the sky' and 'its edges'. The upper world is maximally illuminated and it is characterized by the epithets 'shining', 'radiant', and 'white'. An entrance to the lower world could include any hollow, gorge, cave; it is painted in certain colors: black, yellow, colorful, colorless. Everything there looks like a mirror reflection: a horses' hair grows inside, not outside, the trees grow with their roots upwards. The middle world is the border between the upper and lower worlds. People inhabit it; the moon and the sun shine above him. 'The middle world somewhat 'takes off the contradictory peculiarities of the upper and lower worlds, being the middle of the Universe, a synthesis of three worlds' (Lvova et al., 1988).

The symbols are characterizing the model of the world: 'According to the worldview of nomads, the tree is closely connected with the life of clan members; therefore, many Tengrian traditions, rites and rituals are associated with this symbol of life' (Ashiraliev, 2008). In the view of ancient nomads, the birch is an analogue of the world tree; in epic works, it is a poplar, performing the role of connecting tool with Tengri, who lives in the sky.

The cosmogonic pictures' origin and development of the Universe are considered in close interaction with formation of nomads' ideas on soul, cults of fire, birds, horse, etc, the appearance of primitive forms of religion, ritual practices.

Ashiraliev (2008), Zhukovskaya (1988) specified the awareness of the importance of studying the space as one of the brightest representatives of Tengrian world picture. Abdrasulova and Urmanbetova (2009), Mukhambetova (2002), viewing spatial-temporal model of the world, describe the parameters of cosmogonic representations of Turkic peoples, in the context of ideological constants of culture, in detail: world tree, world mountain, etc. The model of the Universe, implemented in universal image of the world tree with its equivalents - the tree of life, the tree of fertility, the tree of the center, the tree of ascent, the tree of descent, shamanic tree and others - are widely represented in studies of Toporov (1987). Ibraev (1980) describes the world tree:

The pristine Kok-tobe (celestial sacred mountain) grows in the center of the world, Great Baiterek (literally, a great poplar) grows on top of it, the four branches of which in every tier cover the entire sky, permeating all its levels. Its roots penetrate through all earth levels to the bottom water...

The image of a tree as

the visual embodiment of the concept of the world is related to the role of a tree in primitive people's lives: the wood, as the main material, was used to make the instruments of labor and housing; a wood was a source of fire, food, clothing (Zelenin, 2004).

Sacred trees were used as amulets - protectors from evil spirits; a tall tree was a place for collective prayers, or sacrifices. There is still a tradition of tying ribbons on the branches of trees growing near the water sources, a tribute to the veneration of spirits, a sign of place holiness.

The analogue of the Universe, equivalent to the world tree, is 'a world mountain (Toropov, 1987), sacred center of the Universe, ancestral territory, vertical, binding together all three worlds' (Lvova et al., 1988). A tree and a mountain were depicted together in a single picture of the Universe, reinforcing the idea of the vertical axis - the center of the world: a tree grows on top of the mountain; the ceremonies of offering sacrifices were carried out around the sacred tree. "Ancient Turkic kagans and people prayed to "the spirit of the sky" on a high mountain, near the 
tree' (Kashgari, 2005).

The sacred mountain, embodying 'the middle world', represented the habitat of 'living beings' and the spirits of the Universe: the mountain is the home of the spirits from 'the middle world', and the territory around is a sacred 'eco-home' of specific clans and tribes (Gantuya, 2011). The spirits from 'the upper world' are descended to the mountain. In the mountain's name TienShan, tien meant 'sky', bearing semantic sense: the 'mountain-sky' embodied the ancient cosmological, religious and mythological notions about the world axis, sacral vertical permeating the Universe and connecting the Sky-Father with Mother-Earth (Gantuya, 2011).

'The model of the world assumes the unity of macrocosm and microcosm, the nature and the human' (Lvova et al., 1988). The head and all the organs - the eyes, nose, mouth, ears and hair - correlate to the upper world - the sky and its important attributes - the sun, moon and the stars. Everything that is on the bottom of the body (legs) correlate to the lower world, the earth (Lvova et al., 1988). Evsyukova correlates the vital center of the man (the navel cord) with 'cosmic center, whence the world unfolded at the moment of creation' (Lvova et al., 1988). As we see, not only a man modelled a Universe inside, but the structure of the Universe with all its analogues were equivalent to a man: 'the head of fire', 'the head of yurt', 'ears of mountains', 'fingers of the tree', 'shoulder-blade of the earth', 'the armpits of the earth' (Lvova et al., 1988). Tales, legends and myths confirm the anthropomorphic origin of the Universe.

The most common cult among the Central Asian nations was the cult of a horse with spatial connotation that symbolized the idea of three worlds' interpenetration - lower, middle and upper. The winged horse is the symbol of movement: the fire horse, the bird horse. In nomadic ritual practice, a horse was the main sacrificial animal. The horse was often devoted to a certain deity; the animal pastured among other cattle, but it became 'the property' of a deity. The horse was endowed with magical properties of a defender from evil, disease and misfortune. In the mythopoetic consciousness, the hero happens to be in other world, the lower or the upper, always on a horseback; he moves rapidly with horse's help. White coloration of the horse was also related to the sky: only the supreme rulers and shamans, who received this supreme power as a gift of heaven, rode them.

We find the images of winged horses related to the cult of sun on the crown that adorned the head of Saka warrior, the images of the solar horses are found in ancient Indian mythology, where it is associated with wood, solar corona, and their movement - with the movement of the sun over the world (Bose, 2003).

Seasonal migrations, frequent change of pasture as a nomadic lifestyle and existence were connected with a necessity to survive in severe conditions, the conservation of livestock, and protection of fertile layer of soil. The change of landscape, climatic zones, moving under the open sky generated the relevant requirements to nomadic life: the ability to navigate in time and space, to predict weather changes; errors in the timing of migrations could end with a loss of livestock.

Life experience, which passed from generation to generation, was composed of millennial knowledge of the laws of nature; a nomadic way of life dictated tough conditions and each subject, including the yurt, instruments of labor, utensils, clothing, tools, etc were extremely functional. Nomads created a peculiar and distinctive culture that is well adapted and finely balanced with nature; its highest manifestation was a nomadic civilization with a spirit of mobility, flexibility, fresh thinking and the romance of adventure, no attachment to the 'ballast' of material excess, the spirit of collectivism and resistance. 
The yurt was a mobile tool during the endless migrations, its portable construction made it possible to put up or dismantle the dwelling in a short period of time, to go easily from place to place, which was quite important during peacetime and warfare.

Its concentric circular plan is based on an ancient model of the world; first creators designed it as an object of cosmological architecture. Bakan (a long pole), that raises the tunduk (roof window) from the center of the circle, arranged from kerege (walls carcass) is the symbol of the axis of the world. Uwyk (carcass part) that connected with kerege (female beginning) meant that the family has a future, the continuation of the clan.

The construction of the yurt is rational: wooden lattice and pieces of felt performed the function of a temperature regulator, keeping permanent thermal regime inside the dwelling. The structure of nomadic yurt with its tunduk (roof window) pointing skyward let nomads determine the time at night looking at the stars, and at daytime - by the sunbeam coming into the yurt through tunduk. The poles of the dome were a good guide for observing the movement of the moon, stars and planets at night. The yurt was a kind of a family 'planetarium' that made it possible to accumulate and pass the observations over stars from generation to generation. Tunduk, the cross in the middle of the circle, the symbol of Tengrism, completed the construction. 'The yurt is interpreted in mythology as the model of the Universe, bagan is a world axis, connecting the sky (top) and the earth (bottom), that passes through the present and the past, through space-time continuum' (Zhukovskaya, 1988).

Being a horizontal and vertical model of the Universe, the yurt represented a three-part projection. The upper world is a sky (the dome of the yurt, tunduk symbolized the celestial hemisphere, where the sky was the most important part). The middle world is the earth (the inner circle of the yurt was in the role of a middle world, and its circular walls represented a strip of a land's surface). The lower world is the underworld (the role of the lower world was assigned to the central area of the inner circle, where there was a fireplace, associated with the underworld). An entrance to the yurt, threshold and adjacent space were associated with the lower world, as a transitional zone between the outer world and the home, between the stranger's and the own, negative and positive (Lvova et al., 1988). Bosaga - the threshold of the yurt was located on the eastern side.

The whole set of behavior standards associated with the yurt were strictly observed. The specificity of these standards was determined by the limited living space of the yurt, despite which all members of the family and the guests were comfortable inside it. The standards concerned the behavior near the fireplace designed for heating, cooking and lighting, arrangement of the utensils, location and seating positions of people of different ages and social ranks, etc. The place opposite the entrance was the most honorable and was called tör. This place was for guests and there stood chests with carpets, blankets, pillows and clothing on it that showed the social position of the owner. The female half of the yurt was to the left of the tör, where they kept utensils, the food and where they cooked. On the right side - the male half, they kept weapons, supplies to care for cattle and hunting, horse equipment, harness, etc.

Immersion into the inner world, tolerance of domestic inconvenience, smoothness and regularity of movements, slowness and friendliness are typical features of a nomad. The words Shanyrak buik bolsyn! and Let the shanyrak of your yurt be lifted high! were best wishes for the hosts.

Living in a single space-time, going by a measure as the basis for comprehension of the world, the nomad did not violate a harmonious relationship with nature. For example, the 
number of deer, red deer, kulan, saiga was regulated by the special hunting rules and was determined by the concept of 'take only the necessary', 'don't kill animals for fun', it was forbidden to hunt in calf-bearing period, in the period of milk feeding. The hunter's love to the wildlife is not an abstract principle, but the human state, who sees the joy and drama in animals' lives and understands that he himself can become someone's trophy someday.

The world of classical nomads is the world without strong walls, separating people from each other, a world without borders marked on the ground. A sense of unity with the world raised the sense of hospitality: to have the rare guest seated on the honorable place - tör, to feed him with delicious lamb, meat, to offer him a drink made from a mare's milk - kumys, to talk to him on what's happening beyond the line of the horizon.

The hospitality ritual is connected with traditions and is quite complex in its structure. The relationship of the guest and host are determined by the etiquette of hospitality. A guest in the house is a sacred phenomenon, sent from the God that is why he is received with a pomp and goodwill. This solicitous respect to the guest is connected with the nomad's life. Constant movement in the space throughout life, when everyone could happen to be in the place of that traveler, required a careful treatment of the guest, rendering help from the hosts' part. This form of hospitality contributed to the survival of all members of nomadic society in harsh conditions. Guest reception was dictated not only by the above considerations, it gave the opportunity for spiritual fellowship.

The direct contact with the guest replaced the modern mass media. The host could know all the news, details of life of other tribes from the guest, listen to songs and kuis. The host's hospitality etiquette was expressed by the tradition of konak as (cooking meat-special for guests), settling the guest, so that he or her feels comfortable. In turn, the guest also had unwritten responsibilities: to support the conversation, to be a fascinating storyteller, to have a certain horizon of experience, to be able to sing and play the instrument. 'When a guest from afar visits the village, for all the treats he or her was offered he or her asked nothing but only stories' (Levshin, 1832); the host was going to listen to an itinerant singer, who could fill the soul with stories and fairy tales (Karutz, 1972). The distribution of functions in the relationship of host and guest equally stimulated both parties and met their needs.

The ability to think in large temporal and spatial scales inherent in nomads was formed historically, because if one day they fought in Europe, the next day they could have been defending the walls of Middle East fortresses. Nomads loved and honored their motherland and never forgot that this land was home for other nations before them, and after them it may become a homeland for other tribes.

Nomad is primarily a warrior, and the nomadic state is a military organization with a strong centralized khan power; it was distinguished by mobility, power; martial art was developed very well. The practice of nomadic cattle breeding, the use of horses and camels in inaccessible mountainous areas contributed to agility, speed of action.

The wind and percussion musical instruments provided military actions as attributes: surnay, kernei, precussion daulbas, dabyl drums - signal hunting and military percussion musical instruments had caldron-shaped wooden body; its hollow part was covered with cowhide. Their awesome sound scale was an instrument for dictating power, for suppression of will. A part from Aitmatov's novel 'The white cloud of Genghis Khan' (1991) can be a brilliant example. In 'Saryozek execution': 'The powerful rumble of thousands of daulpazs was now his [Genghis Khan] battle cry, his fierce roar, his fearlessness and ferocity, his signal to everyone - to hearken, to rise, to act, to 
move, to conquer the world'. Daulpazs were used as a signal, a battle cry, a call to act, to fight, to conquer. Powerful sounds of daulpaz impelled for absolute obedience.

The huge territory that had been conquered by the nomads for centuries, endless attacks of the enemies, who encroached on the native land, developed the quality of determination in our ancestors in the face of impending danger. With the awareness of dualism of death and life, sorrow and happiness, fragility and strength of spirit, the nomads armed with a spear and a sword, defended their land, their people from invasions. Their motto was 'You can lose wealth, friends, but no inch of own land'. The warriors would receive blessings from the spirits before the battle.

The life and welfare of people depended on the strength, endurance, agility and courage, on the education of young generation. Six and seven year old boys rode horses as good as the best riders as if they were born on saddle, they were taught to handle a horse during the battle, to easily jump from one wildly rushing horse to another, to shoot on the move, to make harnesses, saddles, weapons. The one, who could not handle weapons, was not considered to be a man.

The nomad and his horse make up a single entity, a faithful and fearless companion; the horse accompanied the master in peacetime and wartime. An important sector of husbandry was the breeding of thoroughbred horses. The nomads were proud of their pureblood horses. A good horse could cost a fortune.

Nomads built generic and kindred structures through parental lineage. The warriors built their relations on a mutual trust and they relied on each other during battles, excluding treason, betrayal. The tradition of honoring the spirit of the ancestors obligated the nomads to know their genealogy to the seventh generation. Each man understood that his or her deeds would also be evaluated by seven future generations. According to Tengrian worldview, your sins will pass to your seven coming generations.

There were storytellers, thinkers and retinue singers among military aristocracy. Their works reflected chivalric ideals of a medieval warrior, moral criteria and world outlooks. Willful, uncompromising works praised the courage and commitment to own land; their works gave a new impulse for creative activity, social cohesion. Taking a direct part in the battle, they desperately rushed into the boiling center of the battle and demonstrated contempt for death. Their nomadic consciousness and the code of honor appreciated the valor most of all, which then turned into legends and was praised at mountain fires for centuries; the glory of Tengri departed and ascended with the smoke to the distant sky.

It was a time of poets, warriors, philosophers, thinkers, creators of high art, the time of heroes - batyrs, who determined the life and fate of their nation. As a social phenomenon of knightly brotherhood, they were representatives of the spiritual-military civilization; many of them made military tactical and technological discoveries. Their innovations made it possible to carry out a powerful evolutionary breakthrough of human civilization, becoming the base for the subsequent logistical and socio-cultural progress around the world. Their mobility, continental conquest that shook the universe are impressive. As socially significant individualities with a very wide range of functions, musician-warriors were carriers of a huge amount of information historical, political, social, cultural, domestic and military. Their art was part of the spiritual culture of a nomadic society.

Love, respect and reverent attitude to traditional musicians knew no bounds; at any time of the day or night, they were received as the guests of honor. Creativity, filled with incredible life force impressed people with logic of musical forms that were adjusted down the centuries, with 
subtle figurativeness: horse races on the vast steppe swift as a whirlwind; the roar of victorious battles, the pain of defeat; mourning fallen heroes, calls for further struggle; dancing and happy bustle of national holidays; sublime tributes to the women permeated with love and tenderness, paintings of nature; appealing to distant past; reflections on the transience of life and Sufi strive to unattainable ideal, sorrow about the fate of the nation and tragic prophecy about the future. Distinguished by spiritual core, invincible and divine power, their art inspired to new discoveries and spiritual enlightenment; it was a way of expressing own worldview, world outlook. Impressive achievements of the phenomenon of art would be impossible without an ancient and unique ideological system, an ideological base - Tengrism that survived throughout thousands of years, for which everything is a spirit.

Understanding the music as an entity, reflecting universal space is a way of understanding the world. Music reflected the evolution of seasonal vibrations of nature, organized the social structure of people and entirely fit within Tengrian worldview. Ideology has changed with the adoption of Islam, Buddhism, Christianity, but the language of music that served to other gods and was developed on the sacred basis laid in antiquity, remained to be a Tengrian language; musical sounds, the basic notes and overtones lined up in vertical, aiming at the sky, to Tengri.

\section{Conclusion}

A comprehensive analysis of genesis, traditional culture formation and development is impossible without deep understanding of the successive stages of worldview, world perception and world outlook of people in the context of an integrated system of cosmogonic ideas of nomadic world. This is particularly true with ideological nature of Tengrism, which was an important aspect of the spiritual heritage of Turkic people. The appealing to cultural values of the past, to Tengrism as the phenomenon of the Turkic culture, to ideological aspects will help us better manifest the spiritual, moral and ethical values that have developed over millennia.

A brief retrospective view at Tengrism has enabled us to consider the formation of nomadic national picture of the world; basic rules of balanced communication with the world, that constituted their existence; natural focuses of life predominating in the hierarchy of axiological relations; the meaning of the sky - Tengri, determining its higher status in the system of cults; the responsibility of Heaven for nomad's fate as the creator of spiritual eternity; spatial and temporal patterns to reflect the Tengrian worldview foundations inherent in the level of ethnic subconscious; spiritual information on the world; the landscape, whence once an ethnic group was formed; information lines coming from the depths of centuries through the channels of national traditions, myths, legends.

'Embeddedness' into the natural system of existence has generated a corresponding style of cognition of reality. Harmoniously merging with the primitive world, nomad followed natural cycles, natural flow of life, carrying the genetic material of ancestors. The natural archetypes of nomadic culture, herding, hunting, cattle-breeding way of life and social environment has formed a special attitude to the world.

We attribute the following to ideological orientations of universal lifestyle and culture of the nomads: accepting the life as the highest value; nomadic way of life with the fundamental principle of non-interference to nature; harmonious relationship with the Cosmos, the Universe, Nature; exceptional tolerance of religious faiths, connection with the other world, aruakhs; spirituality, prevailing over transient matter; social structure, institutions of power; tradition of hospitality, hunting rules, logics of nomadic migration, nature of the relationship among tribes 
and nations; the lack of attachment to the material world; conceptualization of spiritual and aesthetic norms of behavior: honor, dignity, freedom, courage, generosity, musicality, spiritual purity - these are not a complete list of spiritual categories that were cultivated by our ancestors.

Thus, in the consciousness of nomads, spatial picture of the world was with strict hierarchy and consistency. The whole phenomenon is viewed through the prism of immanence and naturalism, but not through material advantages displacing the spiritual life. On the contrary, in nomad's spatial representation, material and spiritual elements complement each other being in the eternal unity.

\section{References}

Abaev NV and Ayupov NG (2009) Tengrian civilization in the spiritual, cultural and geopolitical space of Central Asia. Monograph. Kyzyl: Tuvin State University.

Abdrasulova SM and Urmanbetova ZhK (2009) The origins and tendencies of Kyrgyz culture development. Bishkek: ILIM.

Aitmatov Ch (1991) The white cloud of Chingis Khan. Moscow: Planet.

Ashiraliev DzhA (2008) Methodological aspects of studying nomadic culture. Bishkek.

Ayupov NG (2004) Tengrism as an open worldview. Monograph. Almaty: KIE.

Barfeld TJ (2011) The nomadic alternative. Englewood Cliffs, NJ: Prentice Hall.

Bawden CR (2009) The source of religion and morality. London and New York: Kega Paul.

Bezertinov R (2004) Tengrism - the religion of Turks and Mongols. Kazan: Slovo.

Bose A (2003) Pastoral nomadism in India: Problems and prospects. In: Lesnik L and Sontheime GD (eds) Pastoralists and Nomads in South Asia. Otto Harrassowitz: South Asian Institute of the University of Heidelberg Wiesbaden, pp. 1-15.

Fedorova EV (2011) Revisiting the issue of reviving sacred complexes of Siberian Turkic Tengrian prayers. In: III International scientific-practical conference "Tengriism and epic heritage of Eurasian peoples: Origins and modernity". Abakan: Khakassk Books.

Gantuya M (2011) Philosophical comprehension of the concept of "tenger" (Tengerism and the Mongols). Ulaanbaatar: TSALIG.

Gribb R (2004) Nomads in archaeology. Cambridge, MA: Cambridge University Press.

Ibraev B (1980) Cosmogonic representations of our ancestors. USSR decorative arts 8: 40-44.

Karutz R (1972) Among the Kirghiz and Turkmen in Mangyshlak. St. Petersburg: Devrien's Book.

Kashgari M (2005) Divan Lugat al-Turk. Almaty: Dayk-Press.

Khomushk OM (2005) Religion in the culture of Sayan-Altaian nations. Moscow: Russian Presidential Academy of National Economy and Public Administration.

Kodar AA (2012) Turkic languages as the abode of the Tengri (the experience of hermeneutic analysis). Tamur 33. Retrieved from http://tamyr.org/? $\mathrm{p}=1855$

Levshin A (1832) Description of Kirghiz-Kazakh or Kirghiz-Cossack hordes and steppes (Part 3). St. Petersburg: Karl Krayl Press. 
Lvova EL, Oktyabrskaya IV et al. (1988) Traditional worldview of Southern Siberian Turks. Space-time. The real world. Novosibirsk: Nauka (Siberia affiliate).

Makarova OI (2013) A. Appadurai: Cultural dimension of globalization. Herald of Lomonosov Moscow State University 3: 33-37.

Morgan D (2000) Genesis and structure of the ancient nomads' worldview. Oxford: Blackwell.

Morokhoeva ZP (2014) The past as experience for the future. In: Meeting at Baikal: The burden of the past, the challenges of the future. Ulan-Ude: Buryat State University.

Mukhambetova AI (2002) Calendar and time peculiarities in Kazakh culture. In: Amanov B and Mukhambetova AI (eds) Kazakh traditional music and XX century. Almaty: Dayk-Press, p. 544.

Nadelyaeva VM, Nasilov DM et al. (eds) (1969) Ancient Turkic dictionary. Leningrad: Nauka.

Stebleva IB (1976) Poetics in ancient Turkic literature and its transformation in early classical period. Moscow: Nauka.

Suleymenov O (2002) Turks in prehistory. On the origin of ancient Turkic languages and scripts. Almaty: Atamura.

Tokarev SA (1990) Early forms of religion. Moscow: Politizdat.

Toporov VN (1987) Myths of the world nations. Moscow: Sovetskaja entsyklopedija.

Urbanaeva IS (1997). Buryat myth about the first shaman as part of the Central Asian doctrine of the Tengeri. In: International scientific-theoretical conference "Banzarov reading-2". Ulan-Ude: Buryat Scientific Centre of Siberian Department of Russian Academy of Sciences.

Zelenin D (2004) Tree totems in legends and rites of European peoples. Moscow: Indrik.

Zhukovskaya NL (1988) Category and symbolism in the traditional Mongol culture. Moscow: Nauka. 